ISSN 2306-1561

Automation and Control in Technical Systems (ACTS)

2014, No 1.2(9), pp. 165-171.

DOI: $10.12731 / 2306-1561-2014-1-30$

\title{
Temperature adjustment and its impact on the bituminous concrete sealing quality
}

\section{Suvorov Dmitiy Naumovich}

Russian Federation, Doctor of Technical Sciences, Professor, Department of «Automation Industrial Process».

State Technical University - MADI, 125319, Russian Federation, Moscow, Leningradsky prospekt, 64. Tel.: +7 (499) 151-64-12. http://www.madi.ru

\section{suvorovdn@gmail.com}

\section{Dzhabrailov Khizar Abubakarovich}

Russian Federation, Postgraduate Student, Department of «Automated Control Systems».

State Technical University - MADI, 125319, Russian Federation, Moscow, Leningradsky prospekt, 64. Tel.: +7 (499) 151-64-12. http://www.madi.ru

\begin{abstract}
This article contains analysis of how temperature adjustment affects at the quality of bituminous concrete paving sealing. The key objective proposed by this paper is to develop the optimal temperature control mode of bituminous concrete mix throughout technological cycle. Represented temperature control mode applies to regulate values of ultimate strength, density and residual porosity.
\end{abstract}

Keywords: temperature control, sealing, bituminous concrete quality. 
ISSN 2306-1561

Автоматизация и управление в технических системах (АУТС) 2014. - №1.2(9). - С. 165-171.

DOI: $10.12731 / 2306-1561-2014-1-30$

\section{УДК 681.3}

\section{Влияние температуры асфальтобетонной смеси на качество ее уплотнения}

\section{Суворов Дмитрий Наумович}

Российская Федерация, доктор технических наук, профессор кафедры «Автоматизация производственных процессов».

ФГБОУ ВПО «Московский автомобильно-дорожный государственный технический университет (МАДИ)», 125319, Российская Федерация, г. Москва, Ленинградский проспект, д.64, Тел.: +7 (499) 151-64-12, http://www.madi.ru

\section{suvorovdn@gmail.com}

\section{Джабраилов Хизар Абубакарович}

Российская Федерация, аспирант кафедры «Автоматизация производственных процессов».

ФГБОУ ВПО «Московский автомобильно-дорожный государственный технический университет (МАДИ)», 125319, Российская Федерация, г. Москва, Ленинградский проспект, д.64, Тел.: +7 (499) 151-64-12, http://www.madi.ru

Аннотация. В статье проведен анализ влияния температуры асфальтобетонной смеси на качество уплотнения. Этот показатель необходим для создания оптимальных способов управления температурой асфальтобетонной смеси на всем протяжении технологического цикла. Установлено влияние температуры смеси на предел прочности, плотность и остаточную пористость.

Ключевые слова: управление температурой, уплотнение, асфальтобетон, качество.

\section{1. Введение}

На сегодняшний день одной из основных проблем процесса уплотнения асфальтобетонных покрытий является создание режима наиболее эффективного уплотнения, применяемого для различных типов асфальтобетонных смесей $[1-6]$. Качество работ уплотняющей техники и производительность зависит от выполнения комплекса мероприятий, проводимых в зависимости от:

- строительных свойств уплотняемого материала (напр. модуль упругости);

- требований к качеству уплотнения; 
- технологию производства работ по устройству дорожного покрытия (изменение интенсивности уплотняющей нагрузки, влияние температуры на уплотнение, влияние времени действия уплотняющей нагрузки, влияние количества проходов катка, влияние весовых параметров катка, влияние толщины слоя смеси и влияние скорости уплотнения).

На их основе осуществляется обоснованный выбор средств уплотнения и технологических режимов производимых работ.

Одним из важнейших факторов, влияющих на качество и степень уплотнения, является температура уплотняемой асфальтобетонной смеси. Для установления зависимостей влияния температуры на физические параметры смеси был использован экспериментальный способ.

\section{2. Модели и методы исследования}

В лаборатории изучалось влияние температуры асфальтобетонных смесей на процесс уплотнения. Температура смесей варьировалась в диапазоне от 80 до 180 0С. Исследовались типы и виды асфальтобетонных смесей, которые значительно отличались по своим структурно-механическим, строительно-техническим и технологическим свойствам. Выбор смесей также определялся в соответствии с процентом применения в конструктивных слоях дорожных одежд. Уплотнение производилось на испытательном стенде (рисунок 1) а также с помощью форм для изготовления цилиндрических образцов (рисунок 2) на кафедры «Дорожностроительные машины». Измерения производились в соответствии с ГОСТ 12801-98 «Смеси асфальтобетонные дорожные и аэродромные, Методы испытаний» [7].

Для проведения экспериментальных работ использовались асфальтобетонные смеси следующих типов и видов:

- высокопористый горячий песчаный асфальтобетон марки II (модельная смесь № 1)

- пористый крупнозернистый горячий асфальтобетон типа A, марки II; (модельная смесь № 2)

- плотный горячий песчаный асфальтобетон типа Д, марки II, (модельная смесь № 3)

- плотный горячий мелкозернистый асфальтобетон типа Б, марки I. (модельная смесь №4). 


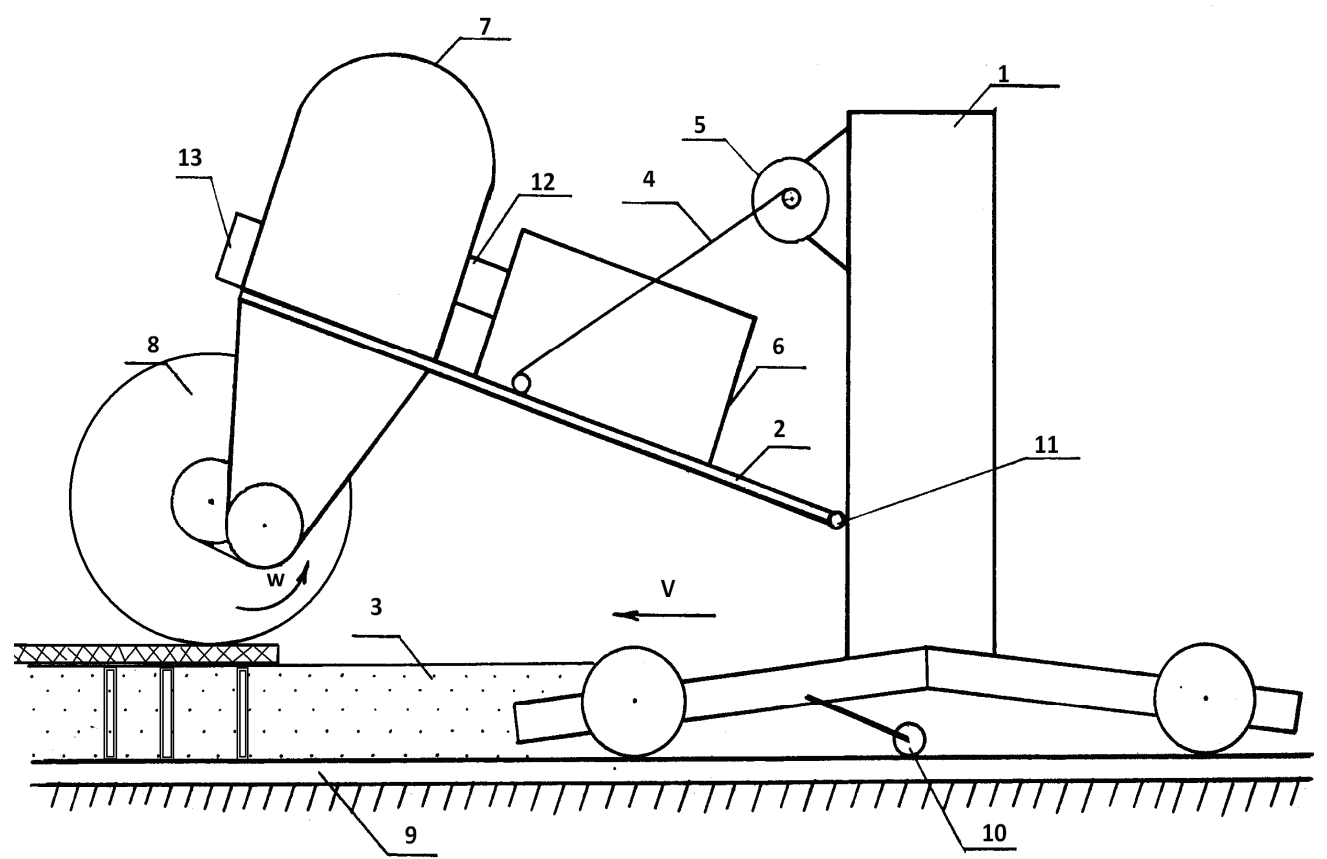
1 - тензометрическая
тележка;
2 - рама;
6 - двигатель вальца;
11 - датчик силы тяги;
7 - червячный редуктор;
12 - датчик момента на двигателе;
3 - уплотняемый
8 - валец;
13 - датчик частоты материал;
9 - направляющие вращения
4 - ограничитель
опускания рамы;
5 - двигатель; элементы;
10-датчик скорости перемешения;

Рисунок 1 - Схема установки уплотняющего оборудования на стенде

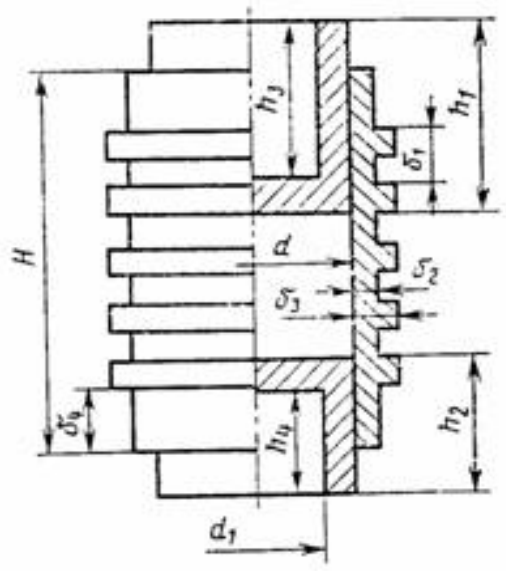

a) форма одиночная облегченная



б) форма одиночная обычная

Рисунок 2 - Формы для изготовления цилиндрических образцов 


\section{3. Результаты исследования}

На основании результатов проведенных экспериментов, были построены графики функциональных зависимостей параметров уплотнения смеси от температуры (рисунки $3-5)$.

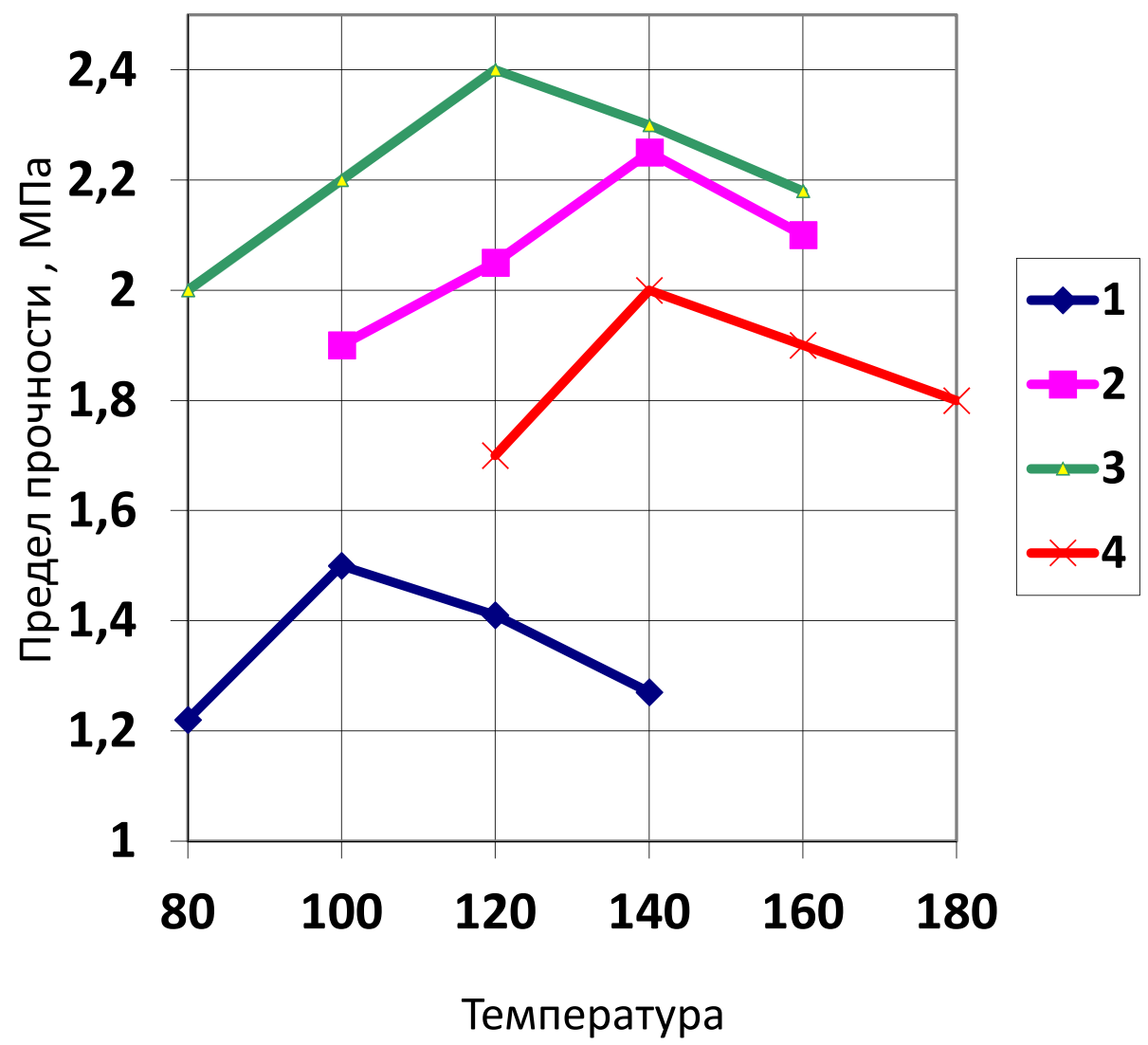

\section{Рисунок 3 - Влияние температуры уплотнения на предел прочности при сжатии} асфальтобетона при $20^{\circ} \mathrm{C}$

Исследование на представленных выше рисунках зависимостей, показывает, что изменение плотности, прочности и остаточной пористости при различных температурах смеси в процессе уплотнения в указанных пределах носит экстремальный характер [8 - 10]. Интенсивность достижения экстремума, полученной функции, на нисходящей ветви у показателя прочности смесей более выражена. Характер изменения таких свойств как плотность и прочность смесей зависят от их вида и типа. Так с увеличением температуры песчаных асфальтобетонных смесей экстремум плотности более выражен, чем в смесях остальных типов. Абсолютные значения оптимальной температуры смеси для уплотнения сдвигаются в область больших значений температуры. 


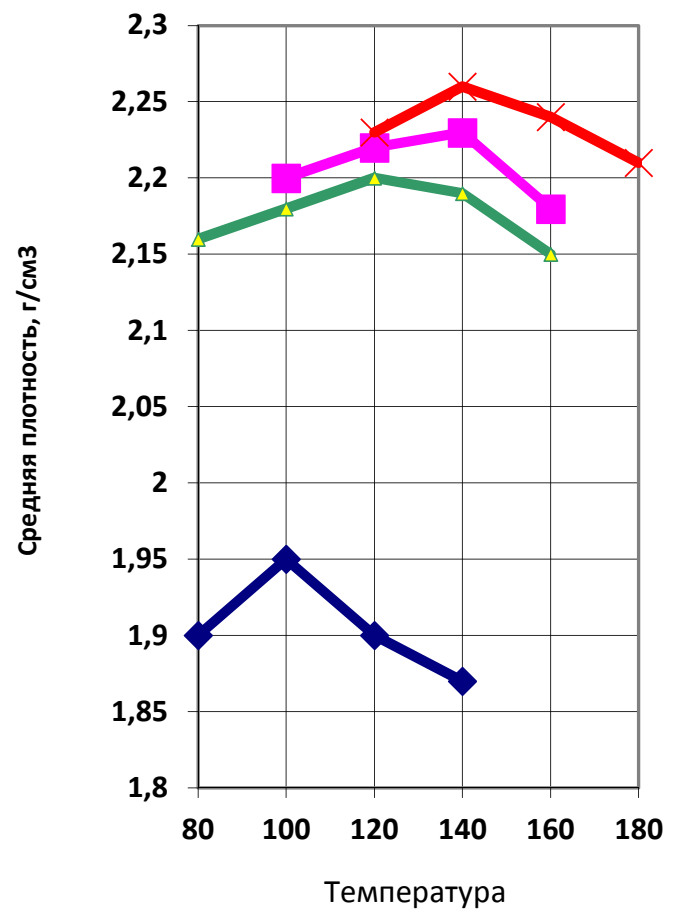

Рисунок 4 - Влияние температуры уплотнения на плотность асфальтобетона

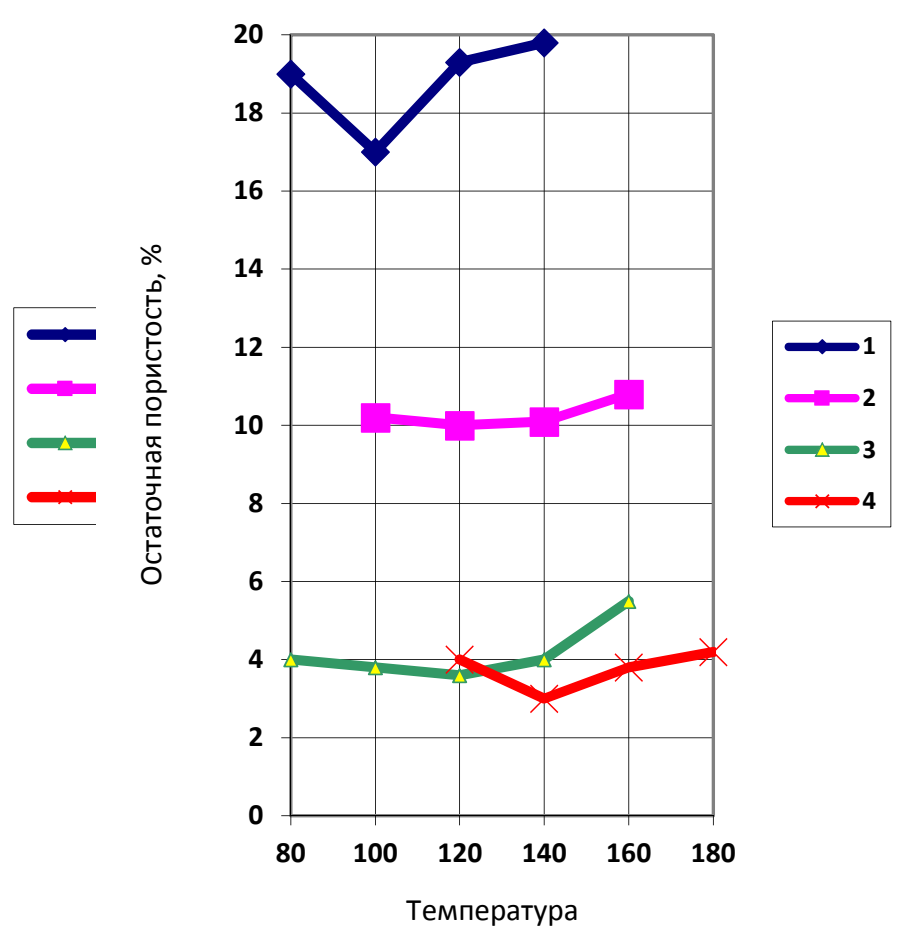

Рисунок 5 - Влияние температуры уплотнения на остаточную пористость

\section{5. Заключение}

Полученные экспериментальным способом данные, по мнению авторов, являются «отправной точкой» для формирования концепций и методов управления температурой асфальтобетонной смеси на всем протяжении цикла, что в дальнейшем в совокупности со всеми методами, применяемыми в технологических процессах укладки дорожных покрытий, позволит улучшить долговечность, качество, а также оптимизировать эксплуатационные свойства дорожных покрытий при минимальных затратах ресурсов.

\section{Список информационных источников}

[1] Зубанов М.П. Вибрационные машины для уплотнения бетонных смесей и грунта. - М.: Машиностроение, 1964. -195 с.

[2] Котлярский Э.В. Формирование структуры и свойства асфальтобетона в процессе уплотнения. Дис. к.т.н., МАДИ. - М.: 1990, - 223 с.

[3] Кустарев Г.В., Салиба И.М. Обобщенный показатель эффективности уплотняющих машин. МАДИ. - М.:1993, - 93с.

[4] Прусов А.Ю. Выбор рациональных режимов работы вибрационных катков при уплотнении асфальтобетонных смесей: Дис. к.т.н.: 05.05.04: Ярославль, 2003, $181 \mathrm{c}$.

[5] Сергеева Т.Н. Исследования взаимодействия вальца катка с асфальтобетонным слоем при его уплотнении: Автореф. Дис. к.т.н.:1981, - 17с. 
[6] Хархута Н.Я. Методы и средства уплотнения асфальтобетонных дорожных покрытий: Исследования рабочих процессов строительных и дорожных машин. Ярославль, 1983. - 12-15 с.

[7] ГОСТ 12801-98. «Смеси асфальтобетонные дорожные и аэродромные, Методы испытаний». - М.: Изд. стандартов, 1998.

[8] Остроух А.В. Автоматизация и моделирование работы предприятий по строительству промышленных объектов: дис. ... д-ра техн. наук: 05.13.06: защищена 07.04.09: утв. 19.06.09. - М., 2009. - 357 с.

[9] Остроух А.В. Автоматизация и моделирование работы предприятий по строительству промышленных объектов: автореф. дис. ... д-ра техн. наук: 05.13.06. - М., 2009. - 43 с.

[10] Остроух А.В. Исследование начального периода моделирования на точность среднеинтегральной оценки имитационных моделей / А.В. Остроух, А.А. Солнцев, Н.В. Солдатов, К.А. Новицкий, П.С. Якунин // Вестник МАДИ. - 2010. Вып. 2(21). - С. 61-65. 